EXTENDED REPORT

\title{
Bone loss in unclassified polyarthritis and early rheumatoid arthritis is better detected by digital $x$ ray radiogrammetry than dual $x$ ray absorptiometry: relationship with disease activity and radiographic outcome
}

\author{
T Jensen, M Klarlund, M Hansen, K E Jensen, J Pødenphant, T M Hansen, H Skjødt, L Hyldstrup, \\ the TIRA group
}

Ann Rheum Dis 2004;63:15-22. doi: 10.1136/ard.2003.013888

See end of article for authors' affiliations

Correspondence to:

T Jensen, MD, PhD,

Department of

Rheumatology, 232, H:S

Hvidovre Hospital,

Kettegaard Allé 30, DK-

2650 Hvidovre, Denmark;

twj@dadlnet.dk

Accepted 23 May 2003

\begin{abstract}
Objective: To compare changes in regional bone mineral density (BMD) of the metacarpal joints measured by dual $x$ ray absorptiometry (DXA) and digital $x$ ray radiogrammetry (DXR) in relation to disease activity and radiographic outcome in a two year follow up study of patients with early RA and unclassified polyarthritis.

Patients and methods: 72 patients with symmetrically swollen and tender second and third metacarpophalangeal or proximal interphalangeal joints for at least four weeks and less than two years were included. 51 patients fulfilled the ACR criteria for RA. 21 patients had unclassified polyarthritis. The patients with RA were divided into groups according to mean disease activity, average glucocorticoid dose, and MRI and $x$ ray detected bone erosions in the hands. Clinical and biochemical measurements were made every month and an $x$ ray examination of the hands and BMD of the metacarpal joints every six months.

Results: DXR BMD decreased significantly only in patients with RA from month 6 and was associated with the mean disease activity. Patients with RA and erosive as well as non-erosive disease showed a significant decrease in the rate of bone loss, greatest in those with erosive disease. No changes in BMD measured by DXA were seen in any patient group.

Conclusion: DXR is a useful measure of the destructive disease activity in patients with RA and unclassified polyarthritis, providing valuable information about bone changes associated with disease activity and erosive disease in early RA. DXR is better than DXA for detecting and monitoring periarticular osteoporosis of the metacarpal bone.
\end{abstract}

$\mathrm{R}$ heumatoid arthritis (RA) preferentially affecting the small joints of the hands (and feet) leads to various degrees of destruction of periarticular tissues, including juxta-articular regions. ${ }^{1}$ Although most patients develop destructive joint disease within the first two years after disease onset, most patients with recent onset RA are characterised by normal hand $x$ rays despite clinical involvement of the small joints in the hands. ${ }^{2}$ The destructive potential is a distinctive feature of RA, separating it from most other inflammatory joint diseases. However, the course of early arthritis is heterogeneous and owing to the lack of a pathognomonic test for RA, diagnosis rests on a composite of clinical and laboratory observations. ${ }^{3}$ Therefore, it remains a clinical challenge to separate self limiting arthritis from RA. Conventional methods, such as clinical assessment and acute phase response (for example, erythrocyte sedimentation rate (ESR) and serum $\mathrm{C}$ reactive protein (CRP)), known to correlate with disease activity are not sufficiently sensitive in a single individual subject as differences still exist between clinical and biochemical disease activity and the development of (irreversible) bone damage. ${ }^{4-8}$

Conventional radiography is considered to be the "gold standard" in the evaluation of the cumulative degree of bone damage caused by $\mathrm{RA}^{,}{ }^{9}$ but is insensitive to bone changes in early disease. One of the earliest radiological manifestations and an important radiological feature of RA is metacarpal osteopenia that may precede erosions. ${ }^{9}$ Radiologically, osteopenia may be seen in the absence of erosions or joint space narrowing, but osteopenia may only be detected at a reduction of $30-50 \%$. The joint inflammation process is probably one of the strongest mediators of focal, articular bone loss in RA. ${ }^{10-13}$ Because the hand is the site of the earliest radiological changes, precise quantification of bone loss in the metacarpal joints may reflect disease activity and predict joint destruction. Recently, dual $x$ ray absorptiometry (DXA) measurement of the hand was applied in RA in the evaluation of periarticular bone loss, and an association with functional impairment, disease duration, and radiological outcome was shown. ${ }^{14-18}$ A new approach for performing radiogrammetry from hand/forearm radiographs, digital $x$ ray radiogrammetry (DXR), has been developed attempting to bridge the gap between radiogrammetry and densitometry. ${ }^{19}$ A recent report has demonstrated a relationship between DXR bone mineral density (BMD) and cortical thickness

\footnotetext{
Abbreviations: ACR, American College of Rheumatology; AUC, area under the curve; $B M D$, bone mineral density; $C R P, C$ reactive protein; DMARDs, disease modifying antirheumatic drugs; DXA, dual $x$ ray absorptiometry; DXR, digital $x$ ray radiogrammetry; ESR, erythrocyte sedimentation rate; GC, glucocorticoid; $\mathrm{HAQ}$, Health Assessment Questionnaire, $\mathrm{MCl}$, metacarpal index; $M C P$, metacarpophalangeal; MRI, magnetic resonance imaging; NSAID, non-steroidal antiinflammatory drug; RA, rheumatoid arthritis; RF, rheumatoid factor; ROls, regions of interest; VAS, visual analogue scale
} 
and DXA BMD, disease duration, and radiological joint destruction. ${ }^{20}$

This study aimed at comparing changes in regional BMD of the metacarpal joints measured by DXA and DXR with disease activity and radiographic outcome and assessing the applicability of BMD changes as markers of disease activity and of erosive joint disease in patients with early RA and unclassified polyarthritis.

\section{PATIENTS AND METHODS}

Seventy five patients (60 women and 15 men, aged 20-82 years) with symmetrically swollen and tender second and third metacarpophalangeal (MCP) or proximal interphalangeal joints for at least four weeks and less than two years and receiving non-steroidal anti-inflammatory drug (NSAID) treatment at baseline were included. The patients were followed up at monthly intervals for up to two years. Three patients (one with RA and two with unclassified polyarthritis) were excluded from the study owing to other diseases that might have influenced the measurements (ovarian cancer, hepatitis $\mathrm{C}$, and alcoholic liver disease). At baseline, 44 patients fulfilled the American College of Rheumatology (ACR) classification criteria for $\mathrm{RA}^{3}{ }^{3}$ and seven patients fulfilled the criteria within the first eight months of the study period. Twenty one patients had unclassified polyarthritis. Seventeen patients withdrew within the first year and four patients within the second year for the following reasons: one RA patient died (pulmonary embolism), 18 patients owing to lack of compliance (five patients with RA and 13 patients with unclassified polyarthritis), and two patients (one patient with RA and one patient with unclassified polyarthritis) moved to other parts of the country. After one year, nine patients with unclassified polyarthritis and after two years, seven patients were still included in the study. However, two patients with unclassified polyarthritis who had withdrawn returned for the 24 month examination.

The patients with RA were treated according to a strategy aiming at promptly suppressing inflammation with NSAIDs, disease modifying antirheumatic drugs (DMARDs) and glucocorticoids (GCs). Ten patients with RA were treated with methotrexate, 39 with sulfazalasine, and one was treated with chloroquine. Twenty seven patients changed DMARDs during the study. Four patients with unclassified polyarthritis were treated with sulfazalasine. Forty six of 51 patients with RA were treated with prednisolone. The cumulative mean (SD) dose during the two year study was 1738 (357) mg; the mean dose during the first year was 773 (145) $\mathrm{mg}$ and during the second year, 966 (218) mg. Ten of the patients with unclassified polyarthritis were treated with GCs. The cumulative mean dose during the two year study was 351 (232) mg; the mean dose during the first year was 172 (116) $\mathrm{mg}$ and the mean dose during the second year was 179 (116) mg.

For the analysis, patients with RA were divided into two groups according to disease activity, based on the variables, expressed in time integrated values (area under the curve (AUC); the weighted mean), calculated for each patient during the first six months: Active disease was defined by: ESR $>20 \mathrm{~mm} / \mathrm{lst} \mathrm{h}$ or $\mathrm{CRP}>95 \mathrm{nmol} / \mathrm{l}$ and $\geqslant 1$ swollen joint $(\mathrm{n}=28)$; and inactive disease by: no swollen joints $(\mathrm{n}=22)$. The disease activity was also based on the weighted mean during the first 12 and 24 month study periods.

Additionally, the patients were divided into two groups according to their annual average GC dose during the two year study: mean dose $\geqslant 2 \mathrm{mg} /$ day and mean dose $<2 \mathrm{mg}$ / day.

Irrespective of the classification of the patients with RA into groups according to disease activity or GC treatment resulting in different numbers of patients in the groups, all calculations are based on the patients with available radiographs after one year $(n=46)$ and two years $(n=44)$.

The patients were followed up by clinical and biochemical control measurements every month during the study. The clinical examination included the registration of the number of tender and swollen joints, the patients' and doctors' global assessments recorded on a visual analogue scale (100 mm, $\mathrm{VAS}_{\mathrm{pt}}$ and $\mathrm{VAS}_{\mathrm{dr}}$ ) and a Health Assessment Questionnaire (HAQ) score according to the core set of disease activity measures as defined by the ACR. ${ }^{21} 22$ Serum CRP (normal level $<95 \mathrm{nmol} / \mathrm{l}$ ) was determined by nephelometry (Behring-Werke, Germany), and ESR (normal level $<20 \mathrm{~mm} /$ lst h) was determined by the Westergren method. Rheumatoid factor (IgM RF) was assessed by nephelometry.

In accordance with the Helsinki II Declaration, each patient was informed verbally and in writing about the trial, and all gave their written consent. The study was approved by the local ethical committee.

\section{Measurement of BMD by DXA}

The BMD of the distal $1.5 \mathrm{~cm}$ of the metacarpal bones of the non-dominant hand and the distal part of the non-dominant forearm was measured by DXA using a Norland XR-26 MK II scanner (Norland Scientific Instruments, Wisconsin, USA) and the small animal programme at entry and thereafter every six months (fig 1 ). ${ }^{14}$

The scanning procedure for measuring BMD in the distal part of the non-dominant forearm $\left(\mathrm{BMD}_{\mathrm{arm}}\right)$ was performed along the longitudinal axis of the distal forearm, starting $1 \mathrm{~cm}$ proximal for the distal radioulnar joint and extending $2.4 \mathrm{~cm}$ towards the elbow. ${ }^{14}$ BMD in the metacarpal bones $\left(\mathrm{BMD}_{\mathrm{mcp}}\right)$ were measured at the distal $1.5 \mathrm{~cm}$ of the metacarpal bones $2-5$ at a scanning width of $11 \mathrm{~cm}$ and pixel size of $0.5 .^{14}$

Coefficient of variation of duplicate measurements was $<0.9 \%$ for $\mathrm{BMD}_{\text {arm }}$ and $<1.6 \%$ for $\mathrm{BMD}_{\mathrm{mcp}}$. The long term precision of the DXA scanner was $<0.8 \%$. $^{14}$

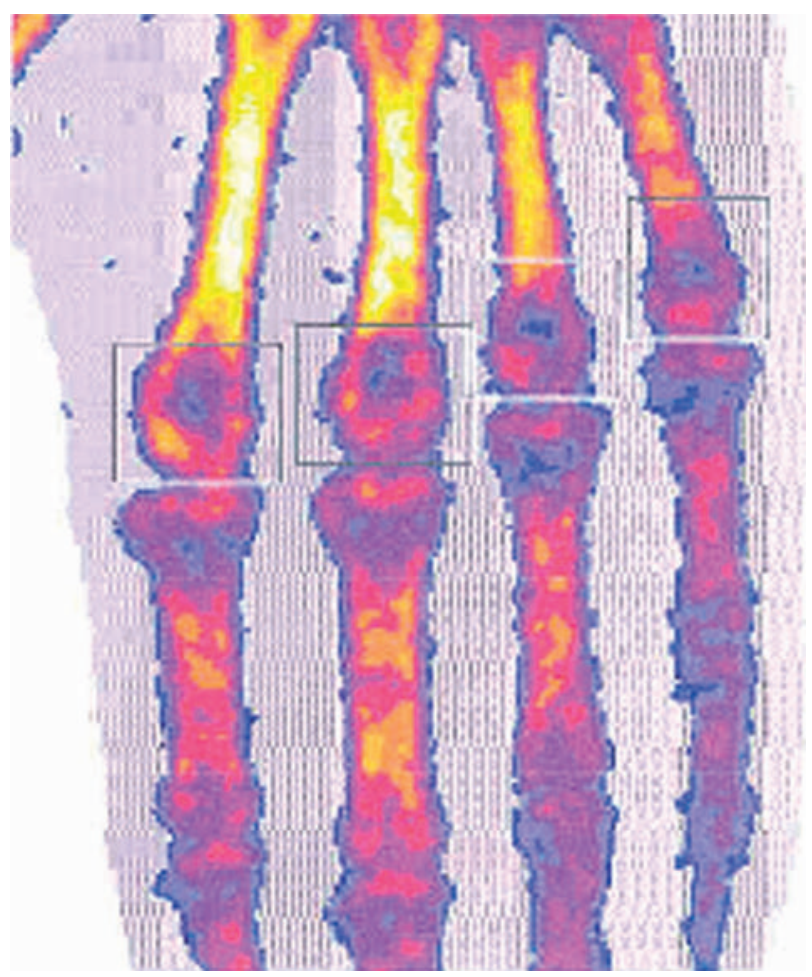

Figure 1 Hand bone densitometry. Measurement of the juxta-articular distal $1.5 \mathrm{~cm}$ of the metacarpal bones. 
The cumulative total radiation dose from scanning the distal forearm and the metacarpal bones was less than $<3 \mu \mathrm{Sv}$.

The reference values for $\mathrm{BMD}_{\text {arm }}$ for women are based on 326 healthy control subjects, aged 18-79 years. A normal reference range for the distal $1.5 \mathrm{~cm}$ of $\mathrm{BMD}_{\mathrm{mcp}}$ was obtained in 108 healthy women (at least 11 women in every decade), aged 18-79 years, and 35 healthy men, aged 29-74 years (median 53 years). At the same time a normal reference range for $\mathrm{BMD}_{\mathrm{arm}}$ in men was established. ${ }^{14}$

\section{Measurement of BMD by DXR}

DXR-BMD was measured on standard radiographs of both hands taken every six months using the X-posure System (Sectra Pronosco A/S, Vedbæk, Denmark). ${ }^{23}$ A flatbed scanner was used to capture radiographs as a digital image $(3600 \times 3600 \mathrm{dpi}$ and 12 bit resolution). The digitised image is subjected to a number of image processing algorithms where the three regions of interests (ROIs) around the narrowest part of the second, third, and fourth metacarpal joints are automatically identified (fig 2 ). In each region, the cortical thickness (CT) and porosity is measured 118 times per $\mathrm{cm}$, symmetrically around the centre of the metacarpal joints. Assuming the bone is elliptical and the bone density is constant, the bone volume per area and a BMD estimate (DXR BMD) are calculated from the CT and given together with the average CT and average metacarpal index (MCI) of the three metacarpal joints. For this purpose, the mid-radius region measured by Hologic QDR-2000 was used as reference. ${ }^{24}$ DXR BMD is consequently measured in $\mathrm{g} / \mathrm{cm}^{2} .^{23}$ The combined cortical thickness of a single metacarpal bone (MCP CT) was calculated as the sum of the ulnar and radial cortical thicknesses (measured in $\mathrm{mm}$ ). The MCI of a single joint (MCP MCI) was calculated as: (the width of the bone-the combined cortical thickness of the bone)/the width of the bone.

The short term precision, coefficient of variation, has previously been determined in 40 pre- and postmenopausal women as $0.65 \% .^{23}$

\section{Radiographs}

Radiographs of hands and wrists in posterior-anterior and Nørgaard projection were taken at the time of inclusion and every six months during the study. All available radiographs were read and scored under "blind" conditions. Each finger and wrist joint was classified as erosive or non-erosive, and each finger and wrist joint was scored according to the Larsen method. ${ }^{25}$ Progression was considered to be any magnitude of increase in the Larsen score or the development of bone erosions.

\section{Magnetic resonance imaging (MRI)}

MRI of the second and fifth MCP joints of the dominant hand was obtained at baseline and at the one year and two year follow up visit on a $1.0 \mathrm{~T}$ Siemens Magnetom Impact Unit (Erlangen, Germany) equipped with a receive only, wrap around surface coil. Continuous axial and coronal, $\mathrm{T}_{1}$ weighted, spin echo images of the hand (TR/TE/slice thickness: $600-700 \mathrm{~ms} / 15 \mathrm{~ms} / 3 \mathrm{~mm}$ ) were obtained before and after intravenous injection of $0.1 \mathrm{mmol} / \mathrm{kg}$ body weight of gadolinium-DTPA (Gd-DTPA, Magnevist, Schering, Berlin, Germany). MR erosions had to be visible on both axial and coronal slices to be diagnosed. The number of MR erosions in each finger joint was counted at baseline and after one and two years. Further details about the procedure have been described elsewhere previously. ${ }^{26}$

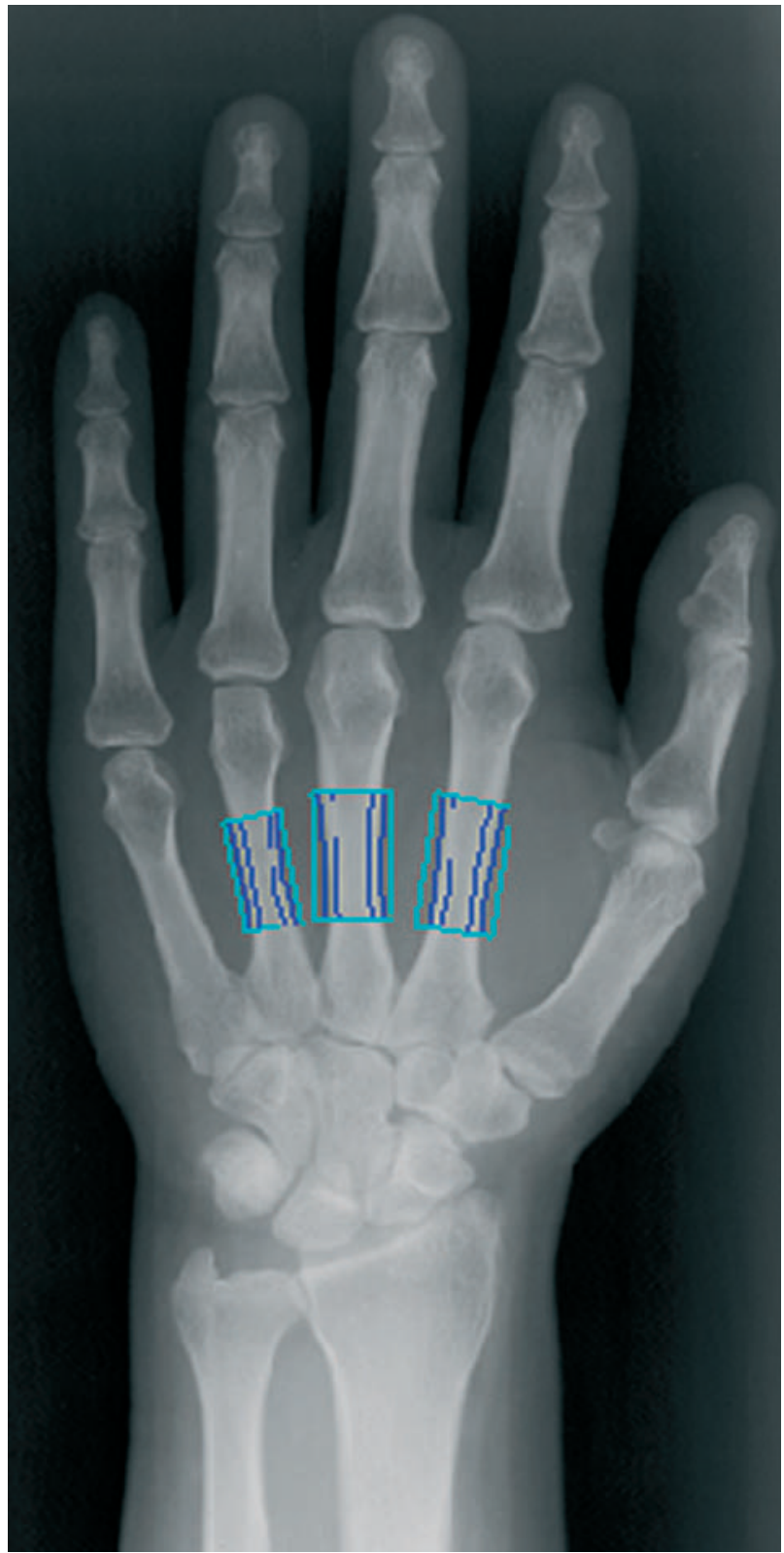

Figure $2 \times$ Ray radiogrammetry. A scanned and processed hand radiograph with the three regions of interests.

\section{Statistical analysis}

The statistical analyses were performed using SigmaStat 2.0 (SPSS Inc, Chicago, IL, USA). Because of the skewed distribution, results are expressed as median and range unless otherwise stated.

To compare the bone mass measurements in the patients with normal age and sex matched levels, the standard deviation (Z) scores were calculated using the equation: (patients' measurement-mean for age and sex matched healthy subjects/standard deviation for the age and sex matched healthy subjects), or the $\mathrm{Z}$ score percentage was calculated using the equation: (patients' measurement/mean for age and sex matched healthy subjects $\times 100$ ). Because only 35 healthy men were available for comparisons of the male patients' $\mathrm{BMD}_{\mathrm{arm}}$ and $\mathrm{BMD}_{\mathrm{mcp}}$, the values are presented as raw data.

Differences between groups were performed using the nonparametric Mann-Whitney rank sum test for unpaired 
differences. Comparison within groups was performed with Wilcoxon's test. Correlation analyses were calculated using the Spearman's $r_{\mathrm{s}}$ test. Values of $\mathrm{p}<0.05$ were considered significant. Changes in the parameters were expressed in time integrated values, and the AUC (the weighted mean) was calculated for each patient during the first six months at seven times (days $0,30,60,90,120150,180$ ), during the first 12 months at 13 times (every month), and during the 24 months at 25 times (every month). ${ }^{27}$

Serial DXA and DXR values for the ROIs were fitted by linear regression for each subject, and the slope of the regression line ( $\alpha$ coefficient) was used to determine the change of the variables from baseline over six months (two measurements) and over 24 months (five measurements).

\section{RESULTS}

Table 1 presents the baseline clinical and demographic features of the patients according to the final diagnoses. Patients with RA were significantly older, had a higher ESR, and more were RF positive than patients with unclassified polyarthritis.

Patients treated with an average GC dose $\geqslant 2 \mathrm{mg} /$ day $(n=19)$ during the two year study had significantly higher values of disease activity-that is, CRP and ESR, during the first 12 and 24 months (data not shown) than patients treated with an average GC dose $<2 \mathrm{mg} /$ day $(\mathrm{n}=32)$.

Among the 51 patients with RA, $46(90 \%)$ had radiographs after one year, and $44(86 \%)$ had radiographs after two years. Twenty two of these patients had erosions in the hands (five of these patients had erosions only detectable by MRI). Table 2 shows baseline characteristics of the patients with RA according to erosive status. At baseline, 13 patients had a Larsen score $>0$ and 10 patients had bone erosions (table 2). Radiological scores progressed in 12 patients (Larsen score: median 6 (range 2-22)) during the two year study. According to annual changes in Larsen score, no significant differences between the disease activity groups were noticed, regardless of whether the disease activity was based on the weighted mean during 6, 12 or 24 months. No differences in annual changes in Larsen score were seen between the groups treated with $\mathrm{GC} \geqslant 2 \mathrm{mg} /$ day and $<2 \mathrm{mg} /$ day.

Table 1 Baseline demographic, clinical, and radiographic characteristics of patients according to the diagnosis of rheumatoid arthritis and unclassified polyarthritis

\begin{tabular}{llll}
\hline & $\begin{array}{l}\text { Polyarthritis } \\
\text { Median } \\
\text { (range) }\end{array}$ & $\begin{array}{l}\text { Rheumatoid } \\
\text { arthritis } \\
\text { Median } \\
\text { (range) }\end{array}$ & $\begin{array}{l}\text { Difference } \\
\text { between } \\
\text { groups * }\end{array}$ \\
\hline Number & 21 & 51 & \\
Sex (female/male) & $18 / 3$ & $41 / 10$ & NS \\
Age (years) & $39(27-80)$ & $54(20-82)$ & 0.004 \\
Disease duration (months) & $3(1-24)$ & $3(1-24)$ & NS \\
Swollen joints (n) & $3(2-13)$ & $6(2-18)$ & NS \\
Tender joints (n) & $16(2-24)$ & $15(2-24)$ & NS \\
ESR (mm/1st h) & $8(2-70)$ & $20(2-105)$ & 0.003 \\
CRP (nmol/l)t & $95(95-247)$ & $95(95-1374)$ & NS \\
IgM RF (positive/negative) & $2 / 19$ & $28 / 23$ & 0.01 \\
Number with Larsen $>0$ & 0 & 13 & \\
Number with bone & 0 & 10 & \\
erosions & & & \\
\hline
\end{tabular}

The patients with early rheumatoid arthritis fulfilled the ACR criteria within one year.

*Mann-Whitney rank sum test for unpaired differences; $p<0.05$; tnormal values: $E S R \leqslant 20 \mathrm{~mm} / 1$ st h, CRP $\leqslant 95 \mathrm{nmol} / \mathrm{l}$.
Table 2 Baseline demographic, clinical, and radiographic characteristics of patients according to erosive and non-erosive rheumatoid arthritis

\begin{tabular}{|c|c|c|c|}
\hline & $\begin{array}{l}\text { Erosive RA } \\
\text { Median (range) }\end{array}$ & $\begin{array}{l}\text { Non-erosive } \\
\text { RA } \\
\text { Median } \\
\text { (range) }\end{array}$ & $\begin{array}{l}\text { Difference } \\
\text { between } \\
\text { groups* }\end{array}$ \\
\hline Number & 22 & 24 & \\
\hline Age (years) & $57(29-82)$ & $50(20-82)$ & 0.04 \\
\hline $\begin{array}{l}\text { Disease duration } \\
\text { (months) }\end{array}$ & $3(1-22)$ & $4(1-24)$ & NS \\
\hline Swollen joints (n) & $7(2-15)$ & $5(2-18)$ & NS \\
\hline Tender joints (n) & $17(2-24)$ & $15(2-22)$ & NS \\
\hline ESR $(\mathrm{mm} / 1 \mathrm{st} h$ & $20(3-50)$ & $16(2-96)$ & NS \\
\hline CRP (nmol/l) & $95(95-1365)$ & $95(95-1374)$ & NS \\
\hline $\begin{array}{l}\text { IgM RF positive/ } \\
\text { negative }\end{array}$ & $11 / 11$ & $12 / 12$ & NS \\
\hline Larsen score $>0$ & $10(0-30)$ & $0(0-2)$ & \\
\hline Bone erosions & $4(0-19)$ & 0 & \\
\hline
\end{tabular}

The patients with early RA fulfilled the ACR criteria within one year.

*Mann-Whitney rank sum test for unpaired differences; $p<0.05$.

\section{BMD measurement}

Only DXR results of the left hand are presented because no further information was obtained by analysis of both hands and only the DXR BMD and DXA BMD of the arm are presented in the figures. The rate of bone loss based on times during the first 6 and 24 months did not differ significantly between the left and right hands, between the metacarpal joints in same hand, or between each other. No significant differences in the annual bone loss between the first and second year were detected in any of the groups by the two BMD methods. Therefore these data are not shown.

No normal controls were studied during the two year study.

\section{DXR and DXA according to the RA and the polyarthritis diagnoses}

In patients with RA, DXR BMD and CT decreased significantly from month 6 and throughout the study (fig 3). The maximum decrease was seen at 24 months with a reduction of $5 \%$ and $7 \%$ in DXR BMD and CT, respectively (fig 3). In patients with polyarthritis, significant changes in DXR BMD or CT were seen after two years (fig 3). Only patients with RA showed significant decreases in MCP CT of the second to fourth metacarpal joints, with a maximum reduction of $6-8 \%$ after two years. However, the rate of bone loss based on the first six and 24 months ( $\alpha$ coefficients), the semiannual (the first six months) or annual bone loss during the two year study did not differ significantly among patients with RA and polyarthritis in any of the DXR parameters.

BMD measured by DXA decreased only significantly in the arm of patients with RA (maximum decrease of $4 \%$ at 24 months, $\mathrm{p}<0.05)$. No changes in BMD of the second to fourth metacarpal joints were seen, and no significant differences in the rates of bone loss or the semiannual or annual bone loss were observed among patients with RA and polyarthritis in any of the measured DXA parameters.

\section{DXR and DXA in relation to disease activity: patients with RA}

In patients with RA with persistently active disease during the first six months as well as patients with inactive disease, the DXR parameters decreased significantly from month 12 and throughout the study period (fig 4). The average bone loss during the two year study period in the DXR parameters in patients with active disease was in the range of $6-9 \%$ (fig 4), while in patients with inactive disease the bone loss was $3-7 \%$ (fig 4 ). No significant differences in the percentage 


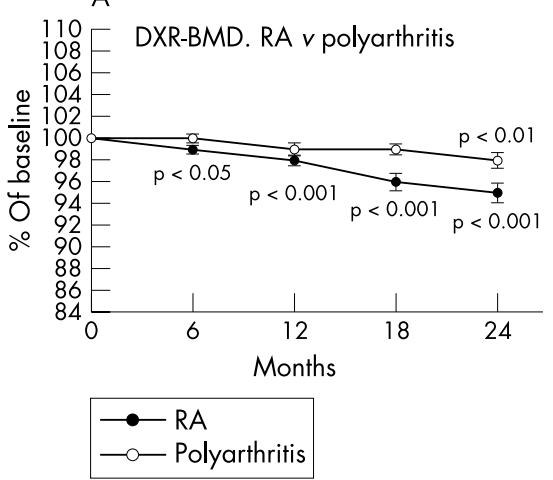

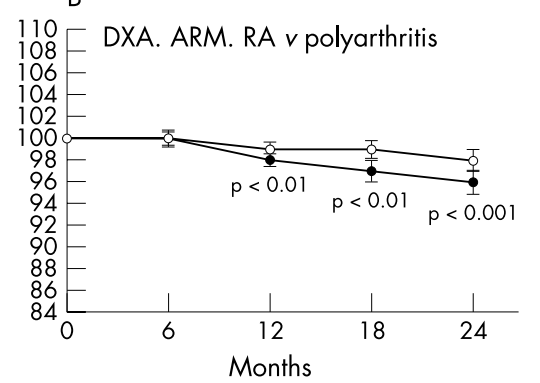

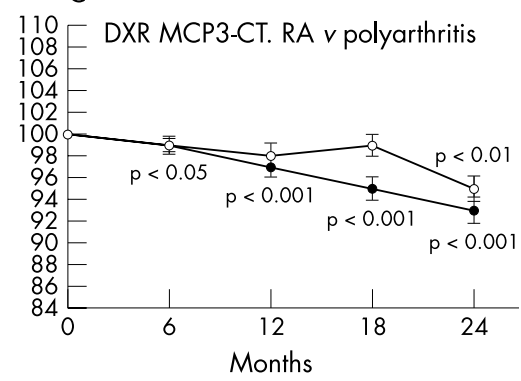

Figure 3 Changes (expressed as a percentage of the baseline value) in the DXR and DXA parameters during the study period in patients with early RA and unclassified polyarthritis. Values are expressed as mean (SEM). p values: comparison within groups with the baseline value by the Wilcoxon test.

change were observed between the two groups of different activity.

Patients with active disease during the first six months of the study had a significantly greater rate of bone loss (based on times during the 24 month study period) in the MCP CT of the third metacarpal $(\mathrm{p}<0.05)$. If persistent disease activity was calculated over 12 and 24 months, no significant differences of the rate of bone loss between patients with active and inactive disease were observed.

According to the DXA technique, patients with active disease during the first six months showed a significant decrease from month 12 and throughout the study period in $\mathrm{BMD}_{\mathrm{arm}}$, and at 24 months in $\mathrm{BMD}_{\mathrm{mcp} 4}$. The average bone loss of the DXA parameters during the two year study period in patients with active disease was in the range of $4-5 \%$ and in patients with inactive disease ranged from a loss of $4 \%$ to an increase of $4 \%$ (data not shown). No significant differences in the percentage change were seen between any of the disease activity groups (based on the weighted mean during 6, 12, or 24 months). A significant difference between the disease activity groups (based on AUC at six months) in the rate of bone loss based on measurements during the 24 months was only seen for DXA MCP3. No significant differences in the rates of bone loss of any of the measured DXA parameters of BMD were seen, if persistent disease was calculated during 12 and 24 months.

In both GC treatment groups, a significant decrease of the DXR parameters from month 12 and throughout the study period was detected, with a maximum decrease in the range of $8-10 \%$ (>2 mg/year at 24 months) and 3-6\% (<2 mg/day at 24 months), respectively. A significant difference in the percentage change between the two groups was seen for the second and third metacarpal joints at 6 and 12 months $(p<0.05)$. Patients treated with a mean dose of GC $>2 \mathrm{mg} /$ day during the study period, had a significantly greater rate of bone loss (based on times during the first six months) in BMD, CT, MCP CT of the third metacarpal $(\mathrm{p}=0.004,0.01$, and 0.002 , respectively). Based on times during the 24 month study period a significantly greater bone loss rate was demonstrated for DXR BMD and MCP CT of the third metacarpal $(\mathrm{p}=0.05, \mathrm{p}=0.02)$.

Measured using the DXA technique, only $\mathrm{BMD}_{\text {arm }}$ decreased significantly from month 12 in both treatment groups with a maximum change of $-6 \%$ to $-3 \%(p=0.01$ and 0.05 ), respectively. The rates of bone loss did not differ between the treatment groups.

\section{Relation to Larsen score: patients with RA}

DXR BMD and CT decreased significantly from month 6 and throughout the study in patients with RA with and without erosions (fig 5). In patients with erosive disease a maximum decrease of $10-7 \%(\mathrm{BMD} / \mathrm{CT})$ was seen at 24 months compared with a maximum decrease of $3-5 \%$ in patients with non-erosive disease (fig 5). A significant difference in the percentage change among patients with erosive RA and patients with non-erosive RA was only seen for BMD and CT at 24 months (fig 5). Likewise, in both patient groups, the MCP CT of the second to fourth metacarpal joints decreased significantly, but patients with erosive RA had a maximum decrease of MCP CT of the second to fourth metacarpal joints
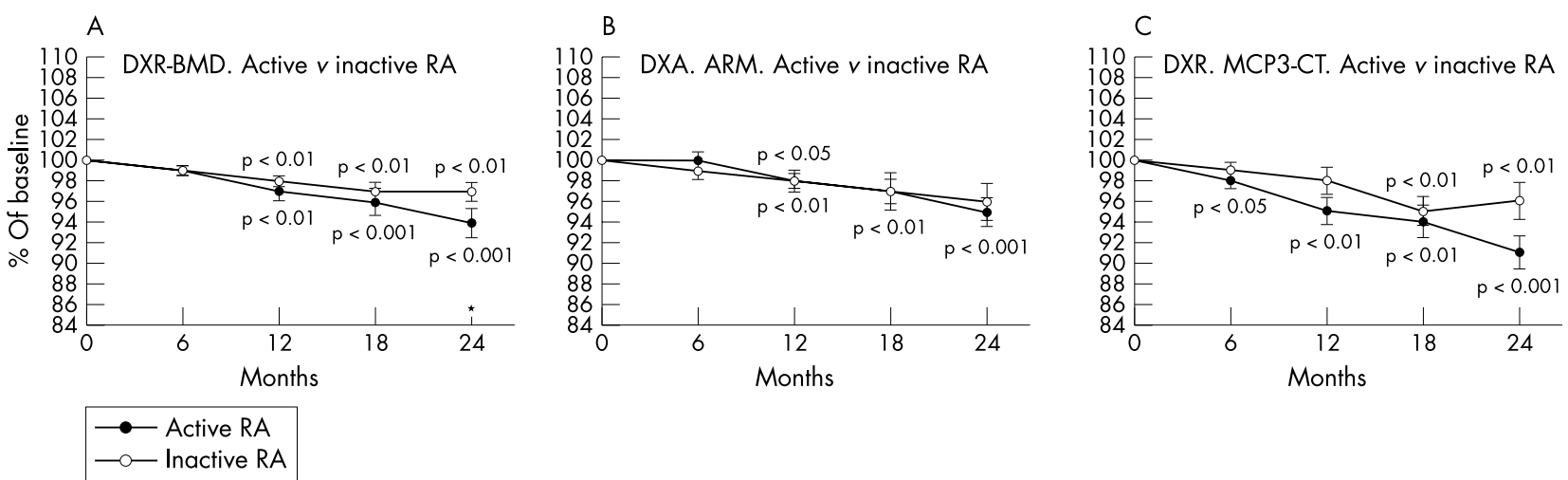

Figure 4 Changes (expressed as a percentage of the baseline value) in the DXR and DXA parameters during the study in patients with active and inactive RA. Values are expressed as mean (SEM). p values: comparison within groups with the baseline value by the Wilcoxon test. Student's $t$ test for unpaired values (that is, the difference between the percentage changes in the variables between the two groups): ${ }^{*} p<0.05$. 


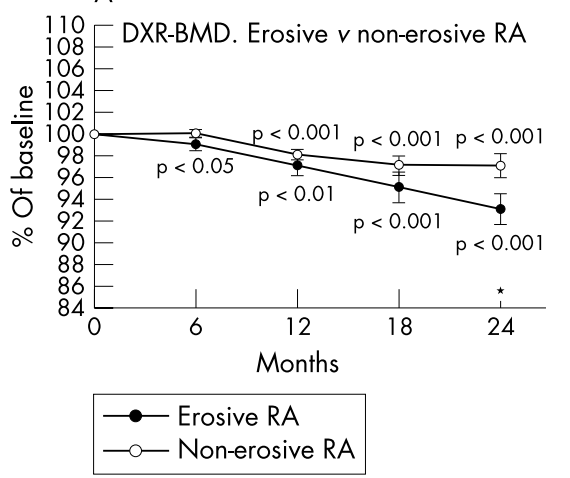

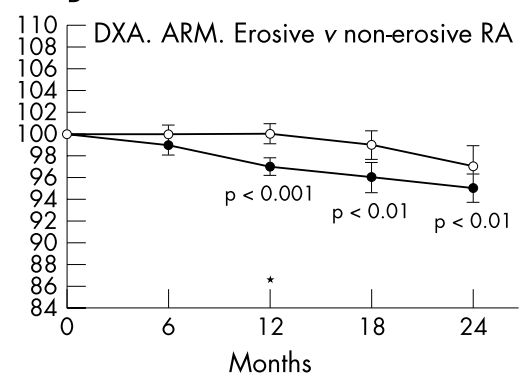

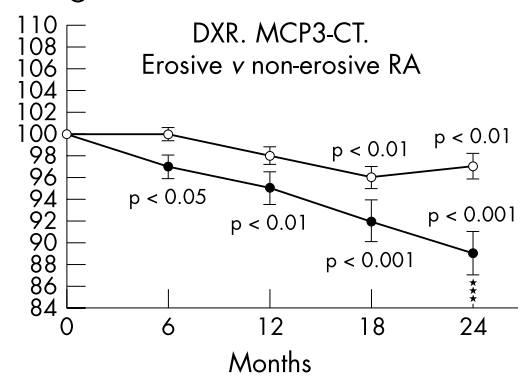

Figure 5 Changes (expressed as a percentage of the baseline value) in the DXR and DXA parameters during the study in patients with erosive and non-erosive RA. Values are expressed as mean (SEM). $p$ Values: comparison within groups with the baseline value by the Wilcoxon test. Student's $t$ test for unpaired values (that is, the difference between the percentage changes in the variables between the two groups): * $p<0.05$.

of $7-11 \%$, whereas patients with non-erosive RA had a significant decrease in the same parameters of 3-6\%. A significant difference in the percentage change between the two groups was only obtained for the MCP CT of the third metacarpal. At baseline, the sex and age adjusted mean value for patients with erosive/non-erosive disease (only calculated for women) was $101 \%$ and $102 \%$, respectively. In both groups a significant decrease was observed with a maximum reduction at 24 months of $8 \%$ in patients with erosive disease compared with $3 \%$ in patients with non-erosive-disease. No significant differences in the percentage changes of the sex and age adjusted mean values of patients with erosive and non-erosive disease were noticed. The rates of bone loss based on times during the first six months as well as during the study period differed significantly in all DXR parameters between patients with erosive and non-erosive disease (table 3).

The rate of bone loss based on times during the first six months and the annual changes in BMD during the first study year and during the two year study period did not correlate with the progression in Larsen score during the first 12 and 24 months. Only the change in MCP CT of the fourth metacarpal during the first 12 months correlated significantly with progression in erosions during the first 12 months $\left(r_{\mathrm{s}}=0.30, \mathrm{p}=0.04\right)$. No significant correlations between the total Larsen score and the parameters of DXR or DXA measurements were seen.

Measured by the DXA technique, a significant decrease was only detected in $\mathrm{BMD}_{\mathrm{arm}}$ in patients with erosive RA (maximum reduction of $4 \%$ at 24 months, $\mathrm{p}<0.001$ ). No differences in the rates of bone loss or annual bone loss were seen in any of the DXA parameters between patients with erosive and non-erosive RA, and none of these DXA parameters correlated significantly with the progression in Larsen score.

Patients were divided into two groups according to the average change in BMD during the 6, 12, and 24 month periods (median value) and the rate of bone loss (median values) based on times during the first six and 24 months of the study in the DXR parameters: BMD, CT, MCP2 CT, and MCP3 CT, and the DXA parameters: BMD of the second to fourth metacarpal joints and BMD of the arm. No significant differences were noticed between these groups in the progression during the two year study in Larsen score or erosions, except for MCP2 CT groups.

Significant correlations were observed between DXR BMD and DXA $\mathrm{BMD}_{\text {arm }}\left(r_{\mathrm{s}}=0.80, \mathrm{p}<0.0001\right)$ and DXR CT of the second to fourth metacarpal joints and DXA BMD $\mathrm{BM}_{\mathrm{mcp}-4}$ $\left(r_{\mathrm{s}}=0.65-0.76, \mathrm{p}<0.0001\right)$.

No further information was obtained when the above calculations were performed on patients without erosions $(\mathrm{n}=20)$ and compared with results for patients with progression in the radiological score during the two year study period $(n=12)$.

\section{DISCUSSION}

The main finding of this study is that a new technology, DXR, not previously used in RA can give useful information on bone changes early in the disease process.

At the initial assessment, female patients had normal age and sex matched DXR BMD, irrespective of diagnoses. During the two year study, a significant bone loss in DXR BMD, CT and age and sex matched DXR BMD of $4-7 \%$ occurred in patients with RA compared with a loss of $1-4 \%$ in patients with unclassified polyarthritis. The bone loss in patients with RA was detectable after six months. Only one

Table 3 The rate of bone loss in the DXR parameters during the first 6 and 24 months of the study period in patients with erosive and non-erosive RA

\begin{tabular}{|c|c|c|c|c|c|c|}
\hline & \multicolumn{3}{|c|}{$\begin{array}{l}\alpha \text { Coefficients during the first } 6 \text { months } \\
\text { of the study }\end{array}$} & \multicolumn{3}{|c|}{$\begin{array}{l}\alpha \text { Coefficients during the } 24 \text { months } \\
\text { of the study }\end{array}$} \\
\hline & Erosive RA & Non erosive RA & p Value* & Erosive RA & Non erosive RA & p Value* \\
\hline $\begin{array}{l}\text { BMD }\left(\mathrm{g} / \mathrm{cm}^{2}\right) \\
C T(\mathrm{~mm}) \\
M C l \\
M C P 2 C T(\mathrm{~mm}) \\
\text { MCP3 CT }(\mathrm{mm}) \\
\text { MCP4 CT }(\mathrm{mm})\end{array}$ & $\begin{array}{r}-0.0011 \\
-0.0060 \\
-0.0006 \\
-0.0120 \\
-0.0222 \\
0.0077\end{array}$ & $\begin{array}{l}-0.0000 \\
-0.0005 \\
-0.0003 \\
-0.0019 \\
-0.0059 \\
-0.0107\end{array}$ & $\begin{array}{l}\text { NS }(0.06) \\
\text { NS }(0.06) \\
\text { NS } \\
\text { NS }(0.06) \\
0.009 \\
\text { NS }(0.08)\end{array}$ & $\begin{array}{l}-0.0014 \\
-0.0057 \\
-0.0006 \\
-0.0098 \\
-0.0109 \\
-0.0078\end{array}$ & $\begin{array}{l}-0.0005 \\
-0.0023 \\
-0.0003 \\
-0.0064 \\
-0.0023 \\
-0.0046\end{array}$ & $\begin{array}{l}0.01 \\
0.02 \\
0.03 \\
0.04 \\
0.008 \\
0.04\end{array}$ \\
\hline
\end{tabular}


previous paper has dealt with the predictive value of BMD changes in the hand in RA and unclassified polyarthritis, showing that BMD of the whole hand measured by DXA decreased only in patients with RA. ${ }^{28}$ These observations support the belief that periarticular osteoporosis is, at least partly, the result of rheumatoid inflammation, probably reflecting the recruitment and activation of osteoclasts mediated by auto- and paracrine mechanisms elicited by the rheumatoid inflammation. ${ }^{12}{ }^{29}{ }^{30}$ Apart from a fall in DXA of the forearm, the DXA technique did not demonstrate any changes in patients with RA, indicating that DXR is better than DXA, probably owing to its better short term precision. The improved precision is the consequence of a fully automated detection of the ROI and the averaging over a substantial number of measurements of CT and bone width. Thus DXR may provide a sensitive tool to measure early bone loss in the hand of patients with RA.

Consistently, periarticular osteoporosis has been associated with disease activity-for example, raised levels of CRP, ESR, and HAQ, and inversely with disease duration, indicating a maximal bone loss in early disease. ${ }^{15} 17$ Compared with patients with inactive disease, the patients with RA with persistently active disease during the first six months appear to have a greater rate of bone loss as measured by the radiogrammetry measures employed: DXR BMD, CT, and MCP CT of the second and third metacarpal joints. On the other hand, no significant differences in the progression in the Larsen score between the two disease activity groups could be demonstrated. Despite improvement of symptoms and reduction in markers of disease activity in the patients with inactive disease, the DXR BMD and MCP CT of the metacarpal joints still decreased significantly. Aging and osteoporosis reduce CT with an annual decrease of about 0.4$0.5 \%$ a year in women. ${ }^{31}$ Because the annual decrease in the CT in patients with active disease averaged $3-4 \%$ and $1-2 \%$ in patients with minor disease activity, the additional bone loss may be ascribed to the inflammatory process itself and the impaired hand function. The tendency towards greater DXR changes in the second and third metacarpal joints than in the fourth metacarpal joint may reflect the frequent involvement of these joints in the rheumatoid inflammatory process and may be in accordance with earlier observations of a more pronounced bone loss in the subregions of phalanges and metacarpal joints in RA than in the entire hand. ${ }^{32}$ These observations indicate that periarticular bone loss may be a marker of disease activity representing the integrated inflammatory activity. Despite improvement in measures of disease activity the bone loss occurred, showing that joint inflammation and/or decreased hand function persists despite disease remission. In addition to DXR BMD, analysis of each metacarpal joint may provide further information on hand bone changes in patients with RA.

Patients with greater disease activity were treated with significantly higher doses of GCs, and patients treated with GCs had significantly higher measures of disease activity during the study period. Radiogrammetry parameters decreased significantly in both steroid treated groups during the study period, but patients treated with the highest dose demonstrated a significantly greater decrease. The mean dose of $2 \mathrm{mg}$ /day is a dose lower than the normal endogen production. The influence of GC on bone metabolism in RA is still a matter of concern. Recent studies indicate that the net effect of GCs on bone turnover in RA may depend on factors such as the balance between the anti-inflammatory effect of $\mathrm{GC}$ and a direct or an indirect effect of GC on bone remodelling. Other studies have demonstrated that treatment with GCs reduces the rate of irreversible joint destruction and delays the development of periarticular osteoporosis (BMD in arm and hand) at the expense of a significant generalised bone loss. ${ }^{63}$ So the greater reduction of BMD parameters in the steroid treated group may be a consequence of persistent inflammation rather than an effect of the small mean dose of GC. Our observations support the hypothesis that changes in hand BMD are associated with rheumatoid inflammatory progression.

Patients with RA with confirmed irreversible joint damage as assessed by radiographs had a significantly higher rate of bone loss in all radiogrammetry parameters than patients without erosions. Both patients with and without erosive disease showed significant decreases in DXR BMD, CT, and MCP CT of the metacarpal joints, but the decrease tended to be greater in patients with erosive disease. A significant, albeit weak, correlation of the rate of bone loss with progression in Larsen score was obtained for the DXR BMD. Only a few studies have dealt with a direct relationship between BMD changes in the hand and the radiological scores. Chan et al found a significant correlation $(r=-0.61)$ between the combined cortical thickness of the second metacarpal and Sharp's score, ${ }^{34}$ and recently, a parallelism between progression in radiological score and decrease in BMD hand and arm has been shown. ${ }^{33}$ DXR seems to provide valuable information about bone changes associated with erosive disease in early RA, whereas DXA seems to be more accurate. However, in this study, the DXR changes did not predict the changes in Larsen score. Nor could any differences in rate of bone loss be established between groups with nonerosive disease and with progressive, destructive joint disease.

The magnitude of the decrease in the DXR parameters and the association with disease activity suggest that the measurements of the mid-shaft metacarpal joints represent periarticular bone loss caused by the rheumatoid inflammation and the functional consequences thereof. It has been demonstrated that hand BMD in patients with RA correlated with BMD of the femoral neck and lumbar spine, but in established as well as in early RA, a greater decrease in periarticular BMD was observed. ${ }^{216}$ In future studies axial BMD measurements of femoral neck and lumbar spine should be made to allow differentiation between generalised and periarticular osteoporosis.

Our study has some limitations due to the sample size and the putative effects of DMARD and/or corticosteroid effect on the variables evaluated. In summary, this study presents the hypothesis that hand BMD measurement by radiogrammetry has the potential to be a useful measure of destructive disease activity in patients with unclassified polyarthritis and early RA. Additionally, DXR seems to provide valuable information about bone changes associated with disease activity and erosive disease in early RA. In achieving information about bone changes in patients with early RA, it might be advantageous to perform subanalyses of each of the second to fourth metacarpal joints. Radiogrammetry seems to be a better technique for detecting and monitoring periarticular osteoporosis of the metacarpal bones than DXA. However, in this study neither the DXR nor the DXA changes predicted progression in the Larsen score.

\section{ACKNOWLEDGEMENTS}

This study was supported by grants from: The Foundation of 17.12.1981; the Danish Rheumatism Association; H:S Forskningspulje, Karen Marie Jørgensen og Datters legat, Novo Nordisk Foundation, Henny og Helge Holgersens Mindelegat and the Danish Medical Association Research Fund.

We appreciated our technicians I. Aagaard, S. Munch, A. Lysgaard and B. Z. Petersen for expert technical assistance.

The TIRA-group (in alphabetical order): M. Hansen, M.L. Hetland, S. Jacobsen, T. Jensen, J.S. Johansen, M. Klarlund, I. Lorenzen, H. Skjødt and M. Østergaard, Rheumatology Research Unit, University of Copenhagen, Hvidovre Hospital. 


\section{Authors' affiliations}

T Jensen, M Klarlund, M Hansen, $H$ Skjødt, Department of Rheumatology, H:S Hvidovre Hospital, University of Copenhagen, DK-2650 Hvidovre, Denmark

M Hansen, Department of Rheumatology, KAS Glostrup Hospital, University of Copenhagen, DK-2600 Glostrup, Denmark

K E Jensen, Department of Radiology, Rigshospitalet, University of Copenhagen, DK-2100 Copenhagen, Denmark

J Pødenphant, T M Hansen, Department of Rheumatology, KAS Herlev Hospital, University of Copenhagen, DK-2730 Herlev, Denmark

L Hyldstrup, Department of Endocrinology, H:S Hvidovre Hospital, University of Copenhagen, DK-2650 Hvidovre, Denmark

\section{REFERENCES}

1 Anderson RJ, Klippel JH, eds. Primers on rheumatic diseases. 11th ed. Atlanta: Arthritis Foundation, 1997:155-74.

2 Lindegaard HM. Early rheumatoid arthritis. Clinical aspects, skeletal imaging and studies on joint related extracellular matrix metabolism. University of Southern Denmark, Faculty of Health Sciences, 2002. [PhD thesis.]

3 Arnett FC, Edworthy SM, Bloch DA, McShane DJ, Fries JF, Cooper NS, et al. The American Rheumatism Association 1987 revised criteria for the classification of rheumatoid arthritis. Arthritis Rheum 1988;31:315-24.

4 Emery $P$, Luqmani R. The validity of surrogate markers in rheumatic disease. Br J Rheumatol 1993;32(suppl 3):3-8.

5 Van Leeuwen MA, van der Heiide DM, van Rijswijk MH, Houtman PM, van Riel PL, van de Putte $L B$, et al. Interrelationship of outcome measures and process variables in early rheumatoid arthritis. A comparison of radiologic damage, physical disability, joint counts, and acute phase reactants. $J$ Rheumatol 1994:21:425-9.

6 Kirwan JR. The effect of glucocorticoids on joint destruction in rheumatoid arthritis. The Arthritis and Rheumatism Council Low-Dose Glucocorticoid Study Group. N Engl J Med 1995;333:142-6.

7 Van der Heijde DM, Remme CA, Hofman DM, Jacobs JW, Biilsma JW. Prediction of progression of radiologic damage in newly diagnosed rheumatoid arthritis. Arthritis Rheum 1995:38:1466-74.

8 Plant MJ, Williams AL, O'Sullivan MM, Lewis PA, Coles EC, Jessop JD Relationship between time-integrated $C$-reactive protein levels and radiologic progression in patients with rheumatoid arthritis. Arthritis Rheum 2000:43: 1473-7.

9 Brower AC. Use of the radiograph to measure the course of rheumatoid arthritis. The gold standard versus fool's gold. Arthritis Rheum 1990;33:316-24.

10 Bresnihan B. Pathogenesis of joint damage in rheumatoid arthritis. J Rheumatol 1999;26:717-19.

11 Kong YY, Feige U, Sarosi I, Bolon B, Tafuri A, Morony S, et al. Activated $\mathrm{T}$ cells regulate bone loss and joint destruction in adjuvant arthritis through osteoprotegerin ligand. Nature 1999:402:304-9.

12 Gravallese EM, Manning C, Tsay A, Naito A, Pan C, Amento E, et al. Synovial tissue in rheumatoid arthritis is a source of osteoclast differentiation factor. Arthritis Rheum 2000;43:250-8.

13 Gough AK, Lilley J, Eyre S, Holder RL, Emery P. Generalised bone loss in patients with early rheumatoid arthritis. Lancet 1994:344:23-7.

14 Hansen M, Florescu A, Stoltenberg M, Pødenphant J, Pedersen-Zbinden B, Hørslev-Petersen $\mathrm{K}$, et al. Bone loss in rheumatoid arthritis. Influence of disease activity, duration of disease, functional capacity and corticosteroid treatment. Scand J Rheumatol 1996;25:367-76.

15 Deodhar AA, Brabyn J, Jones PW, Davis MJ, Woolf AD. Longitudinal study of hand bone densitometry in rheumatoid arthritis. Arthritis Rheum 1995;38:1204-10.

16 Peel NF, Spittlehouse AJ, Bax DE, Eastell R. Bone mineral density of the hand in rheumatoid arthritis. Arthritis Rheum 1994;37:983-91.
17 Devlin J, Lilley J, Gough A, Huissoon A, Holder R, Reece R, et al. Clinical associations of dual-energy $\mathrm{X}$-ray absorptiometry measurement of hand bone mass in rheumatoid arthritis. Br J Rheumatol 1996:35: 1256-62

18 Deodhar AA, Brabyn J, Jones PW, Davis MJ, Woolf AD. Measurement of hand bone mineral content by dual energy $x$ ray absorptiometry: development of the method, and its application in normal volunteers and in patients with rheumatoid arthritis. Ann Rheum Dis 1994;53:685-90.

19 Rosholm A, Hyldstrup L, Bæksgaard L, Grunkin M, Thodberg HH. Estimation of bone mineral density by digital $\mathrm{X}$-ray radiogrammetry. Theoretical background and clinical setting. Osteoporosis Int 2001;12:961-9.

20 Jensen T, Hansen M, Jensen KE, Pødenphant J, Hyldstrup L. Comparison of dual $x$-ray absorptiometry (DXA), digital $x$-ray radiogrammetry (DXR) and conventional radiographs in the evaluation of osteoporosis and bone erosions in patients with rheumatoid arthritis. Submitted to Scand J Rheumatol.

21 Wolfe F, Kleinheksel SM, Cathey MA, Hawley DJ, Spitz PW, Freis FJ. The clinical value of the Stanford Health Assessment Questionnaire Functional Disability Index in patients with rheumatoid arthritis. J Rheumatol 1988; 15:1480-8.

22 Felson DT, Anderson JJ, Boers M, Bombardier C, Chernoff M, Fried B, et al. The American college of Rheumatology preliminary core set of disease activity measures for rheumatoid arthritis clinical trials. The Committee on Outcome Measures in Rheumatoid Arthritis Clinical Trials. Arthritis Rheum 1993;36:729-40.

23 Black DM, Palermo L, Sørensen T, Jørgensen JT, Lewis C, Tylavsky F, et al. A normative reference database study for Pronosco X-posure System. J Clin Densitom 2001;4:5-12.

24 Jørgensen JT, Andersen PB, Rosholm A, Biarnason NH. Digital X-ray radiogrammetry: a new appendicular bone densitometric method with high precision. Clin Physiol 2000;20:330-5.

25 Larsen A, Dale K, Eek M. Radiographic evaluation of rheumatoid arthritis and related conditions by standard reference films. Acta Radiol Diagn 1977;18:481-91.

26 Klarlund $M$, Østergaard M, Jensen KE, Lysgård Madsen J, Skjødt H, Lorenzen I, the TIRA group. Magnetic resonance imaging, radiography, and scintigraphy of the finger joints: one year follow up of patients with early arthritis. Ann Rheum Dis 2000;59:521-8.

27 Matthews JNS, Altman DG, Campbell MJ, Royston P. Analysis of serial measurements in medical research. BMJ 1990;300:230-5.

28 Green MJ, Proudman S, Stewart S, Wakefield RJ, McGonagle D, Conaghan P, et al. Serial hand bone densitometry with Lunar-XL densitometer in the assessment of patients with very early inflammatory arthritis. BrJ Rheumatol 1998;37(suppl):s104.

29 Manolagas SC, Jilka RL. Bone marrow, cytokines, and bone remodelling. Emerging insights into the pathophysiology of osteoporosis. N Engl J Med 1995;332:305-11

30 Romas E, Bakharevski O, Hards DK, Kartsogiannis V, Quinn JM, Ryan PF, et al. Expression of osteclast differentiation factor at sites of bone erosion in collagen-induced arthritis. Arthritis Rheum 2000;43:821-6.

31 Maggio D, Pacifici R, Cherubini A, Simonelli G, Luchetti M, Aisa MC, et al. Age-related cortical bone loss at the metacarpal. Calcif Tissue Int 1997:60:94-7.

32 Alenfeld FE, Diessel E, Brezger M, Sieper J, Felsenberg D, Braun J. detailed analyses of periarticular osteoporosis in rheumatoid arthritis. Osteoporosis Int 2000; 11:400-7.

33 Hansen M, Pødenphant J, Florescu A, Stoltenberg M, Borch A, Kluger E, et al A randomised trial of differentiated prednisolone treatment in active rheumatoid arthritis. Clinical benefits and skeletal side effects. Ann Rheum Dis 1999;58:713-18.

34 Chan E, Pandith V, Towheed TE, Brouillard D, Zee B, Anastassiades TP. Comparison of the combined cortical thickness of the second metacarpal with Sharp's method for scoring hand microradiographs in rheumatoid arthritis. J Rheumatol 1998;25:1290-4. 